\title{
LA FORESTACIÓN DE TIERRAS AGRÍCOLAS EN LA PROVINCIA DE GRANADA. ACCIONES DENTRO DEL PROGRAMA DE ACOMPAÑAMIENTO DE LA NUEVA P.A.C.
}

Juan GÁMEZ NAVARRO*

\section{RESUMEN}

El objetivo de este artículo es analizar la situación actual del sector forestal en la provincia de Granada: superficie ocupada y especies predominantes, regímenes de propiedad, tipos de aprovechamientos, distribución por comarcas y aportación a la Producción Final Agraria (PFA).En segundo lugar, estudiaremos la repercusión que el programa de forestación de tierras agrícolas, subvencionado por la UE, a través de la Política Agrícola Común (PAC), ha tenido en las masas forestales de la provincia, durante los años que ha estado vigente el programa de ayudas (1993/98). También analizaremos las reforestaciones llevadas a cabo por las administraciones públicas en esta provincia y en Andalucía, para así conocer el incremento total de superficie boscosa. Por último, para conocer el incremento real de superficie forestal estudiaremos las causas de los incendios forestales que se han producido en la última década y su incidencia en la pérdida de superficie forestal.

\section{ABSTRACT}

The aim of this article is to analyse the current situation of the forestry sector in the province of Granada: occupied area and main species, land tenures, kinds of crops, distribution by forest regions and contribution to the Producción Final Agraria (Agricultural Final Yield). Secondly, we will analyse the impact of the afforestation of farmland programme, which is subsidized by the EU, through the Common

\footnotetext{
* Catedrático de Geografía e Historia de I.E.S., Granada
} 
Agricultural Policy, on the afforestation of the province during the aid programme period (1993/98). We will also analyse the reforestations carried out by the Civil Service in this province and the region of Andalusia in order to know the total increase of wooded land. Finally, to know the real increase in forest areas we will study the causes of forest fires in the last decade and their impact on the loss of wooded area.

\section{INTRODUCCIÓN}

Pretendemos en este artículo analizar la situación actual del sector forestal en la provincia de Granada, su aportación a la PFA de Granada, y, a la vez queremos poner de manifiesto la repercusión que el programa de forestación de tierras agrícolas, subvencionado por la UE, a través de la Política Agraria Común (PAC), ha tenido en la provincia en los años comprendidos entre 1993-1998. También analizaremos las reforestaciones llevadas a cabo por las administraciones públicas en esta provincia y en Andalucía. Estudiaremos las causas de los incendios forestales y la superficie quemada para conocer el incremento real que ha tenido la masa forestal granadina. El análisis geográfico nos lleva a su estudio a nivel comarcal que pretendemos realizar en base a los únicos datos disponibles a este nivel, que son los que aportan las Cámaras Agrarias Locales.

\section{EL SECTOR FORESTAL EN LA PROVINCIA DE GRANADA}

\subsection{Evolución de la superficie forestal}

Para realizar el análisis estadístico de la importancia y evolución de la superficie forestal en Granada nos vamos a ceñir a los datos referidos al último cuarto de siglo, época que coincide con decisivos cambios políticos, que lógicamente han tenido su repercusión en todos los aspectos económicos de la vida. Entre los que afectan al sector forestal está la desaparición de los anteriores organismos estatales que coordinaban la acción sobre el bosque, caso del ICONA, por otros de nueva creación (Agencia de medio Ambiente de Andalucía en 1984, como unidad de gestión para el manejo de los recursos naturales andaluces, posteriormente integrada en una nueva Consejería, la de Medio Ambiente), y el traspaso de las competencias forestales a las CC. AA. En el caso de Andalucía las competencias sobre montes y forestales se adjudicaron al Instituto Andaluz de Reforma Agraria (IARA, 1984), que colaboró en la redacción del Plan Forestal Andaluz aprobado en 1989 (GÓMEZ MENDOZA, 1992, 95). 
CUADRO 1.

EVOLUCIÓN DE LA SUPERFICIE FORESTAL GRANADINA EN COMPARACIÓN CON LA ANDALUZA Y ESPAÑOLA (1974 - 2001) (DATOS EN HAS. Y EN \%)

\begin{tabular}{|c|c|c|c|c|c|c|}
\hline \multirow{2}{*}{ AÑO } & \multicolumn{2}{|c|}{ GRANADA } & \multicolumn{2}{|c|}{ ANDALUCÍA } & \multicolumn{2}{|l|}{ ESPAÑA } \\
\hline & TOTAL & $\%$ & TOTAL (miles) & $\%$ & TOTAL (miles) & $\%$ \\
\hline 1974 & 250.900 & 20,0 & 2.280 & 26,1 & 14.716 & 29,1 \\
\hline 1975 & 260.800 & & 2.380 & 27,3 & 14.943 & 29,6 \\
\hline 1976 & 289.900 & 23,1 & 2.485 & 28,5 & 15.248 & 30,2 \\
\hline 1977 & 289.900 & 23,1 & 2.486 & 28,5 & 15.242 & 30,2 \\
\hline 1978 & 290.000 & 23,1 & 2.640 & 30,2 & 15.403 & 30,5 \\
\hline 1979 & 290.500 & 23,2 & 2.633 & 30,2 & 15.506 & 30,7 \\
\hline 1980 & 290.400 & 23,2 & 2.672 & 30,6 & 15.598 & 30,9 \\
\hline 1982 & 291.000 & 23,2 & - & - & - & - \\
\hline 1983 & 290.400 & 23,2 & 2.651 & 30,4 & 15.566 & 30,8 \\
\hline 1984 & 289.000 & 21,1 & 2.613 & 29,9 & 15.543 & 30,8 \\
\hline 1985 & 289.000 & 23,1 & 2.611 & 29,9 & 15.614 & 30,9 \\
\hline 1986 & 288.800 & 23,0 & 2.660 & 30,5 & 15.675 & 31,0 \\
\hline 1987 & 270.300 & 21,6 & 2.595 & 29,7 & 15.662 & 31,0 \\
\hline 1989 & 279.200 & 22,3 & 2.616 & 30,0 & 15.696 & 31,1 \\
\hline 1991 & 280.400 & 22,4 & 2.654 & 30,4 & 15.858 & 31,4 \\
\hline 1992 & 283.700 & 22,6 & 2.644 & 30,3 & 15.915 & 31,5 \\
\hline 1993 & 284.200 & 22,7 & 2.349 & 26,9 & 16.136 & 31,9 \\
\hline 1994 & 287.700 & 23,0 & 2.652 & 30,1 & 16.146 & 31,9 \\
\hline 1995 & 284.200 & 22,7 & - & - & - & - \\
\hline 1998 & 290.500 & 23,2 & 2.603 & 29,8 & 16.412 & 32,5 \\
\hline 2000 & 291.500 & 23,3 & 2.571 & 29,5 & 16.521 & 32,7 \\
\hline 2001 & 291.500 & 23,3 & 2.575 & 29,5 & 16.521 & 32,7 \\
\hline Incremento & 40.600 & 16,2 & 327 & 14,3 & 1.805 & 12,2 \\
\hline
\end{tabular}

Fuente: Anuarios de Estadísticas Agrarias de España y Anuarios de Estadísticas Agrarias y Pesqueras de Andalucía.

Nota: el porcentaje se calcula con respecto a la superficie total de cada una de las tres unidades geográficas que se comparan. La superficie geográfica de Granada es de 1.253,1 miles de has; la de Andalucía, 8.726,7 y la de España, 50.471,2 miles de has. 
El cuadro 1 pone de manifiesto que el incremento de la masa forestal en Granada ha sido de unas 40.000 has., que supone un 16,2\%, en el último cuarto de siglo y que el porcentaje de la superficie provincial dedicada a estos fines ha oscilado entre el $20 \%$ y el $23 \%$; es decir, entre una quinta y casi una cuarta parte de la superficie provincial está dedicada a explotaciones forestales. En Andalucía el porcentaje es superior en 4 puntos aproximadamente; en cambio en España tenemos los porcentajes superiores al 30\%, excepto en los dos primeros años de la serie, oscilando entre el $30-32 \%$ de toda la superficie geográfica. El incremento porcentual del bosque en el período analizado ha sido superior en Granada $(16,2 \%)$ al que se ha producido en Andalucía (14,3\%) y en España (12,2\%).

El terreno forestal de Granada y de Andalucía se puede clasificar en tres grandes grupos: monte maderable, monte abierto y monte leñoso. En Granada el monte maderable representa el 60,75\%, el monte abierto, el 15,14 y el monte leñoso, el 24,1; en cambio en Andalucía el monte maderable supone el 40,85\%, el monte abierto el 34,01 y el leñoso el 25, 13\% (ANUARIO ESTADÍSTICAS AGRARIAS, 1998).

\subsection{Régimen de propiedad: pública- privada}

Por lo que respecta a la formas de propiedad predominante en estas tierras destaca, como pone de relieve el cuadro 2, el régimen privado, más acentuado en Andalucía que en Granada, con el 71,7\% y el 66,1\% respectivamente. Y dentro de este capítulo la mayoría pertenecen a particulares, el $95 \%$ en ambos casos, y el resto a entidades locales. Entre los bienes de titularidad pública los ayuntamientos acaparan la mayor parte con un porcentaje que supera el $64 \%$ en Granada, siendo menor el de Andalucía. Poco ha variado la situación respecto a los datos incluidos en el Plan Forestal Andaluz referidos a la década de los ochenta, época en la que los montes en manos de particulares representaban en Andalucía el 73\% y en Granada, el 66,9\% (PLAN FORESTAL, 1989, 51).

Este predominio del sector privado en los montes, que originariamente eran públicos se debe a diferentes avatares históricos entre los que destacan la apropiación durante la etapa de la reconquista, la venta en pública subasta durante la desamortización de Madoz de 1855 y las diferentes formas de apropiación que han ido mermando paulatinamente el patrimonio de ayuntamientos, como roturaciones arbitrarias, posteriormente legalizadas y usurpaciones de los grandes aprovechando su situación de dominio en los concejos (COBO, 1992; LÓPEZ ESTUDILLO, 1992; GÁMEZ, 1995). La consecuencia fue el incremento de la superficie cultivada en detrimento del monte a base de tierras, a veces, poco aptas para su explotación agrícola, hecho que ha incidido en la mala conservación del terreno que al quedar 


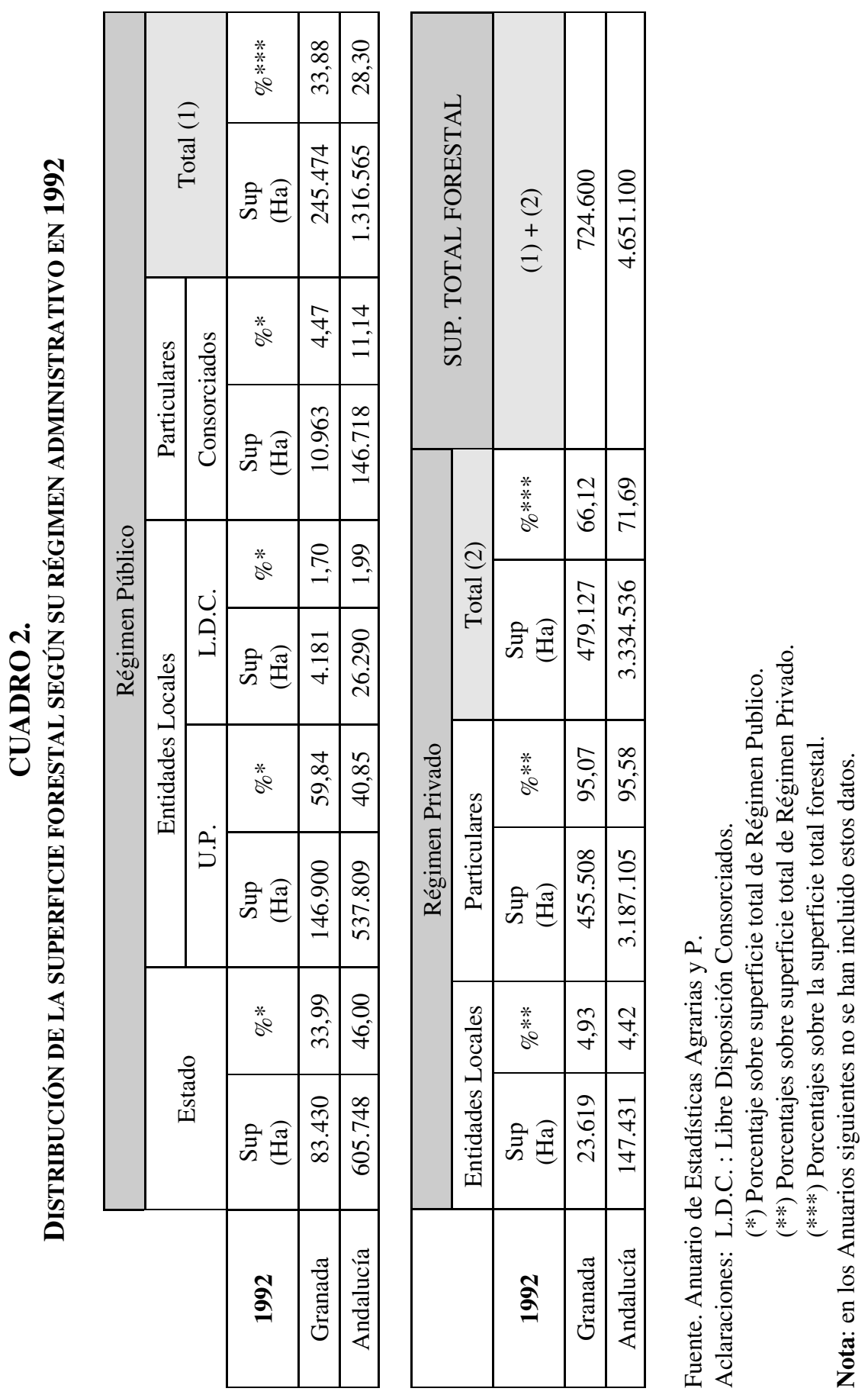


desprovisto de su cubierta vegetal ha sido afectado por intensos procesos erosivos, que han terminado en su abandono. En la actualidad de lo que se trata es que parte de estas tierras agrícolas marginales vuelvan a tener el uso que nunca debieron dejar de tener y que es el único para el que están preparadas por sus características de suelos, pendientes y altitud (HONTORIA, 2002).

\section{IMPORTANCIA ECONÓMICA DEL SECTOR FORESTAL}

\subsection{Tipo de aprovechamientos y valor económico}

Los aprovechamientos del monte van desde el uso y disfrute de la madera para fabricación de muebles y de la leña como combustible a los usos recreativos como pueden ser la caza y la pesca. También pueden recogerse frutos silvestres de escaso valor.

Como se desprende del cuadro siguiente la madera es el aprovechamiento más importante por su valor económico y porque existe una creciente demanda de madera y de productos derivados de ella, aunque los usos lúdicos van en aumento, en relación con la mayor demanda de un uso recreativo del monte, siempre que éste sea compatible con el buen mantenimiento de la cubierta vegetal.

CUADRO 3.

Principales aProvechamientos Forestales. VAlor EN MiLES de Ptas: Provincia de Granada

\begin{tabular}{|l|r|r|r|r|r|r|r|r|}
\cline { 2 - 9 } \multicolumn{1}{c|}{} & $\begin{array}{c}\text { Madera } \\
\text { (en pie) }\end{array}$ & $\begin{array}{c}\text { Leña } \\
\text { (en pie) }\end{array}$ & Corcho & Caza & Frutos & $\begin{array}{c}\text { Pesca } \\
\text { Continental }\end{array}$ & Hongos & Total \\
\hline 1991 & 795.376 & $4.824,3$ & 0 & 79.840 & 0 & 3.780 & 190 & 884.010 \\
\hline 1992 & 357.680 & 36.460 & 0 & 94.300 & 20 & 3.690 & 40 & 491.600 \\
\hline 1993 & 417.430 & 5.640 & 168 & 21.040 & 40 & 3.690 & 349 & 797.630 \\
\hline 1994 & 576.824 & 18.930 & 0 & 99.190 & 40 & 3.690 & 120 & 818.674 \\
\hline 1995 & 614.620 & 650 & 0 & 252.475 & 731.000 & 379.600 & 40 & 1.978 .385 \\
\hline 1996 & 428.360 & 40.710 & 0 & 0 & 0 & 0 & 0 & 471.066 \\
\hline 1997 & 615.117 & 12.664 & 0 & 0 & 0 & 500 & 172 & 630.450 \\
\hline 1998 & 850.633 & 35.456 & 3.200 & 0 & 37.500 & 0 & 171 & 928.958 \\
\hline
\end{tabular}

Fuente: Anuarios de Estadísticas Agrarias y Pesqueras de Andalucía. Elaboración propia.

Nota: en los Anuarios de los años 2000 y 2001 aparecen las cantidades de madera autorizadas para aprovechamientos forestales en montes privados, pero no se incluyen los precios, por lo que no podemos calcular el valor. 
El bosque, de hecho, tiene funciones múltiples que se pueden resumir en las de protección, producción y función social (empleo, recreo y esparcimiento y educación; de ellas son fácilmente computables las de producción, pero no ocurre lo mismo con las de protección y las de tipo social, aunque son las más demandadas en la actualidad, debido a que el monte está dejando de ser una realidad marginal separada y lejana de la ciudad, porque sus habitantes necesitan ámbitos de recreo en los que desarrollar actividades en contacto con la naturaleza (PÉREZ VILARIÑO, 1998, 15).

\subsection{Aportación a la PFA del sector forestal}

La aportación de cualquier subsector a la economía se puede medir tanto en base al PIB que produce como por su aportación a la PFA, criterio que vamos a utilizar en este caso.

Como observamos la aportación del sector forestal granadino al conjunto de su PFA es muy reducida, oscilando entre el $0,85 \%$ y el $2 \%$ (cuadro 4 ); mientras en Andalucía los porcentajes oscilan entre el 1,18 y el 2,23.

En el caso de Andalucía la aportación porcentual es algo superior en algunos de los años considerados en el cuadro, pero su tendencia ha sido muy similar al granadino, pues en ambos casos observamos una tendencia descendente que indica una pérdida relativa de importancia en el conjunto de la producción final agraria hasta el año 2000, pérdida más acusada en el caso de Granada, pues ha perdido más de un punto, mientras el subsector andaluz se ha reducido menos de un punto. En el año 2001 la aportación del subsector forestal granadino a la PFA se ha recuperado, situándose en el $2 \%$ y en Andalucía en el 1,82\%, valores similares a los del año 1995, fecha desde la que no cesaron de disminuir porque el valor de las cosechas se fue reduciendo.

\section{CUADRO 4.}

APORTACIÓN DEL SUBSECTOR FORESTAL A LA PFA (1991-2001. SERIE HiSTÓRICA) (millones de ptas. corrientes y \% de la PFA)

\begin{tabular}{|c|c|c|c|c|c|c|c|c|c|c|c|}
\hline & 1991 & 1992 & 1993 & 1994 & 1995 & 1996 & 1997 & 1998 & 1999 & 2000 & 2001 \\
\hline \multirow{2}{*}{ Granada } & 1.295 & 924 & 952 & 888 & 1.524 & 819 & 990 & 950 & 843 & 716 & 1.691 \\
& $1,43 \%$ & $1,13 \%$ & $1,16 \%$ & $1,15 \%$ & $1,96 \%$ & $0,99 \%$ & $0,97 \%$ & $0,95 \%$ & $0,97 \%$ & $0,85 \%$ & $2,0 \%$ \\
\hline \multirow{2}{*}{ Andalucía } & 16.183 & 16.364 & 16.170 & 13.233 & 16.707 & 13.250 & 15.937 & 16.401 & 14.793 & 16.022 & 23.998 \\
& $1,97 \%$ & $2,23 \%$ & $2,15 \%$ & $1,60 \%$ & $1,88 \%$ & $1,29 \%$ & $1,30 \%$ & $1,31 \%$ & $1,18 \%$ & $1,33 \%$ & $1,82 \%$ \\
\hline
\end{tabular}

Fuente: Anuarios de Estadísticas Agrarias y Pesqueras de Andalucía. 


\subsection{Análisis comparativo de la productividad de los bosques andaluces y españoles}

Conocer la productividad de los bosques andaluces nos obliga a compararlos con los españoles, comparación que permite deducir las siguientes conclusiones:

\section{CUADRO 5.}

\section{ProduCTIVIDAD DE LOS MONTES ANDALUCES}

\begin{tabular}{|l|r|r|}
\hline \multicolumn{1}{|c|}{ Productos } & Andalucía & España \\
\hline Madera ( $\mathrm{m}^{3} /$ ha de superficie boscosa) & 0,83 & 1,60 \\
\hline Leña (estéreos/ha de superfie boscosa) & 0,40 & 0,34 \\
\hline Corcho (kg/ha de alcornocal) & 718,60 & 723,50 \\
\hline Bellota de montanera (kg/ha de quercus) & 456,50 & 291,50 \\
\hline Piñón $(\mathrm{kg} / \mathrm{ha}$ de pino piñonero) & 35,40 & 20,50 \\
\hline Castaña (kg/ha de castaño) & $1.978,70$ & 257,40 \\
\hline
\end{tabular}

Fuente: Anuario de Estadística Agraria, 1992. (Tomado de R. Silva)

La productividad de los bosques andaluces, $\mathrm{y}$, por tanto, granadinos también es mucho más baja que la de España en lo que al producto estrella de los bosques se refiere, la madera, pero en cuanto al resto de los frutos producidos la situación se invierte: en cuanto a la leña la producción de nuestros bosques es muy superior a la de España. El alcornocal andaluz tiene una producción de corcho superior en $5 \mathrm{~kg}$ al español. En la producción de castañas las diferencias se multiplican hasta 7 veces que son las que la producción del bosque andaluz supera al español, con $1978 \mathrm{~kg}$ y $257 \mathrm{~kg}$ respectivamente. Algo similar ocurre en la producción de bellota, pues los bosques andaluces producen $456 \mathrm{~kg}$ superando ampliamente a los de España, con 291.

En definitiva, que las productividades del bosque andaluz en lo que a sus frutos se refiere es más elevada que la del español; en cambio, en lo que a la producción de madera se refiere la situación se invierte.

\section{EL PROGRAMA DE REFORESTACIÓN COMUNITARIO. ADAPTACIÓN DE LA NORMATIVA A ESPAÑA Y A ANDALUCÍA}

\subsection{Reglamentos comunitarios}

El Reglamento del Consejo (CEE) 2080/92 de 30 de junio estableció un programa de ayudas a las inversiones forestales, con una doble finalidad: reducir la superficie agraria y, por tanto, la producción excedentaria de cereales y, en segundo, lugar contribuir a una mejora del medio ambiente, y en particular aminorar el problema 
de la desertificación. Estas medidas forman parte del conjunto de planes o medidas de acompañamiento de la nueva PAC. El programa comunitario se plantea un variado conjunto de objetivos a conseguir, que son:

1) Disminuir el impacto negativo que pudiera derivarse de la aplicación de las medidas de la Nueva PAC

2) Diversificar las actividades de las personas que trabajan en la agricultura

3) Mejorar a largo plazo los recursos forestales

4) Luchar contra la erosión y por la conservación de los recursos hídricos

Posteriormente otros reglamentos que han sido aprobados por el Consejo también tienen repercusión en la reforestación, son:

1.- R. (CE), 1257/99, del Consejo de 17 de mayo de 1999, sobre las ayudas al desarrollo rural a cargo del FEOGA establece la concesión de una ayuda para la reforestación de tierras agrícolas, que podrá incluir los costes de plantación, una prima anual por ha. forestada para cubrir los costes de mantenimiento durante un periodo de hasta cinco años y una prima anual por ha. para cubrir durante un periodo máximo de 20 años las pérdidas por ingresos que suponga la forestación de tierras cultivadas antes de ella.

2.- R. (CE), 1750/99, de la Comisión, de 13 de julio por el que se establecen disposiciones de desarrollo del R(CE) 1257/99.

\subsection{Reales Decretos de adaptación en España}

Las normativas europeas se han ido adaptando a España a través de los siguientes Reales Decretos:

- Real Decreto 378/93, de 12 de marzo

— Orden de 20 de marzo de 1995 y Orden de 28 de diciembre de 1995

- Real Decreto 152/1996, de 2 de febrero

- Real Decreto 6/2001, de 12 de enero

Los nuevos objetivos establecidos son muy similares a los que se incluyeron en el derogado Decreto 378/93, que ha servido para mejorar, en base a la experiencia acumulada a lo largo de estos 7 años, su aplicación. Los objetivos que se marcan son:

- Promover la forestación de tierras agrícolas, contribuyendo a diversificar la actividad agraria, así como las fuentes de renta y empleo. 
- Contribuir a la corrección de los problemas de erosión y desertización que sufren determinadas zonas españolas, así como a la mejora y conservación de los suelos, la conservación de la flora y de la fauna

- Regulación del régimen hidrológico de las cuencas

También debemos mencionar los programas de fomento de las producciones forestales, que han seguido funcionando regularmente los últimos años, permaneciendo inalterables las dos líneas del Ministerio de Agricultura Pesca y Alimentación:

1) Fomento a la producción de madera (M.M.)

2) Fomento de las Producciones No Maderables (M.N.M.).

Además la Comunidad Autónoma Andaluza ha puesto en marcha un plan especial de ayuda al Alcornocal y al Encinar (M.A.E.), establecida mediante Orden de 7 de abril de 1989, para completar las que el MAPA a nivel general había establecido para los bosques de producción no maderable, pero que eran a todas luces insuficientes en Andalucía, dada la importante presencia de masas de estas características, no en vano son los dos árboles prototipos del paisaje mediterráneo.

\subsection{Decretos de la Junta de Andalucía}

Las normativas europeas y española se han ido adaptando a Andalucía a través de los siguientes Decretos:

— Decreto 73/1993 de 25 de mayo y posterior Orden de 27 de julio de 1993

- Decreto 50/1995, de 1 de marzo y posterior Orden de 28 de diciembre de 1995

— Decreto 127/1998 de 16 de junio

La Consejería de Agricultura y Pesca de la Junta mediante el Decreto 73/1993 de 25 de mayo y posterior Orden de 27 de julio de 1993, estableció y desarrolló un régimen de ayudas para el fomento de inversiones forestales en explotaciones agrarias, dando así traslado a la legislación andaluza del Reglamento del Consejo (CEE) 2080/92 de 30 de junio y del Real Decreto 378/1993 de 12 de marzo de adaptación a España de la normativa comunitaria. Por este decreto se establecieron las ayudas para fomentar las inversiones forestales en explotaciones agrarias, que a grandes rasgos pretenden:

a) retirar tierras de la producción agraria, para crear nuevas masas forestales que produzcan beneficios económicos variados, como contribuir a 
b) generar ingresos adicionales a los agricultores mediante la diversificación de sus actividades,

c) a crear empleo rural y a aumentar el interés de los agricultores por la actividad forestal.

El Decreto 73/1993 de 25 de mayo fue desarrollado por la orden de 27 de julio de 1993 y modificado y actualizado mediante el Decreto 50/1995, de 1 de marzo. Con la orden de 20 de marzo se refunden los textos de los decretos 73/1993 y 50/1995, y para su aplicación se publica la Orden de 28 de Diciembre de 1995 que recoge las novedades y modificaciones introducidas en el Decreto 50/1995.

El plan de reforestación contenido en el Decreto 73/1993 tenía una vigencia de cinco años (1993-97), en el transcurso de los cuales se pretendía reforestar una superficie de 250.000 has.: unas 9.000 durante 1993 y 60.250 anuales entre 1994 y 1997. Así pues, la trascendencia que puede tener este programa en Andalucía se reafirma si comparamos estas cifras con el promedio de la superficie reforestada entre 1986 y 1993 al amparo del Programa de Fomento de las Repoblaciones Forestales en montes privados, que asciende a 20.559 Has. en 8 años; es decir a razón de 2.570 anuales (SILVA PÉREZ, R., 1995).

Con fecha 20 de junio de 1998 se ha publicado un nuevo Decreto ${ }^{\circ}$. 127/1998 (BOJA, núm. 68) que sustituye al anterior y que es el actualmente vigente por lo que pasamos a analizar los objetivos que persigue, el importe de las primas que estableció, aún vigentes, hasta tanto no se publique un nuevo decreto que las actualice en la línea de las establecidas por el del MAPA en enero de 2.001 y los tipos de tierras que pueden ser reforestadas.

La relación de objetivos que se pretenden conseguir es la siguiente:

- Contribuir a un proceso de diversificación de la agricultura, adecuando los usos de las tierras al potencial agrológico de las mismas, valorando el papel del árbol en la forma de hacer agricultura

- Luchar contra la desertización, conservando los recursos hídricos, los suelos y la cubierta vegetal

- Proteger los ecosistemas de singular valor natural y las especies en peligro de extinción y mantener aquéllos para garantizar la diversidad biológica

- Restaurar los ecosistemas forestales degradados

- Defender las masas forestales de los incendios, plagas y enfermedades forestales

- Asignar adecuadamente los usos del suelo, para fines agrícolas o forestales, manteniendo su potencial biológico y la capacidad productiva del mismo

- Conseguir una utilización racional de los recursos naturales y el incremento de sus producciones 
- Facilitar la generación de condiciones socioeconómicas que eviten el desarraigo de las comunidades rurales, favoreciendo su progreso

- Diversificar el paisaje rural mediante la conservación y recuperación de enclaves forestales en zonas agrícolas, así como plantaciones lineales, setos vivos y bosquetes

Los beneficiarios de las ayudas son los titulares de explotaciones, tanto sean personas físicas como jurídicas, que perciban al menos un $5 \%$ de su renta de la actividad agraria. También las podrán solicitar agrupaciones de al menos cinco titulares de explotaciones cuyas superficies sean continuas y que se constituyan a estos efectos mediante documento público y por un periodo de 20 años, para realizar en común la forestación, el mantenimiento y gestión de la explotación y la prevención y extinción de incendios.

Los tipos de superficie agraria que se pueden reforestar son los dedicados hasta el momento presente a alguno de los siguientes usos y aprovechamientos:

- Tierras ocupadas por cultivos herbáceos (tierras arables)

- Barbechos

- Huertos familiares

— Tierras ocupadas por cultivos leñosos (frutales, viñedos, olivar, agrios y otros)

- Pastizales

- Alcornocales

- Monte claro

— Eriales a pastos

Quedan excluidos los suelos clasificados legalmente como urbanos y urbanizables y las superficies cuya gestión esté encomendada a la Consejería de Medio Ambiente mediante consorcio o convenio.

Las ayudas o primas establecidas son de tres tipos (ver cuadro 6):

- por gastos de reforestación, para compensar los gastos para llevar a cabo la reforestación de las superficies agrarias (tareas de preparación, desbrozado, compra de especies y realización de la plantación);

- por gastos de mantenimiento y reposición de marras durante los primeros cinco años desde el inicio de la plantación; y

- una ayuda compensatoria por hectárea forestada para compensar las pérdidas de renta derivadas del cambio de uso u aprovechamiento, que se recibirá durante un periodo de 20 años. 
También se establecieron ayudas para la diversificación del paisaje y para la realización de cortafuegos y el establecimiento de puntos de agua.

El importe de las primas lo recogemos en el siguiente cuadro:

\section{CUADRO 6.}

\section{IMPORTE DE LAS PRIMAS EN ANDALUCÍA (PTAS./HA)}

\begin{tabular}{|c|c|c|c|c|c|}
\hline \multirow[t]{2}{*}{ Especies } & \multicolumn{2}{|c|}{$\begin{array}{c}\text { Prima de } \\
\text { Reforestación }\end{array}$} & \multicolumn{2}{|c|}{$\begin{array}{c}\text { Prima de } \\
\text { Mantenimiento }\end{array}$} & \multirow{2}{*}{$\begin{array}{c}\text { Prima } \\
\text { Compensatoria }\end{array}$} \\
\hline & Pts & $€$ & Pts & $€$ & \\
\hline Del Anexo 1 & 152.000 & 913,53 & 25.000 & 150 & \multirow{2}{*}{$\begin{array}{c}\text { C. Herbáceos: } \\
37.500(225,38 €)\end{array}$} \\
\hline $\begin{array}{l}\text { Del anexo } 1+25 \% \\
\text { de los anexos } 2 \text { y } 3\end{array}$ & 170.000 & $1.021,72$ & 30.000 & 180 & \\
\hline $\begin{array}{l}\text { Del anexo } 1+50 \% \\
\text { de los anexos } 2 \text { y } 3\end{array}$ & 195.000 & $1.171,97$ & 30.000 & 180 & \multirow{2}{*}{$\begin{array}{c}\text { C. Leñosos: } \\
30.000(180 €) \\
\text { Barbechos: } \\
25.000(150 €)\end{array}$} \\
\hline $\begin{array}{l}\text { Del anexo } 1+75 \% \\
\text { de los anexos } 2 \text { y } 3\end{array}$ & 215.000 & $1.292,18$ & 30.000 & 180 & \\
\hline Del anexo 2 & 255.000 & $1.532,58$ & 40.000 & 240,4 & \multirow{3}{*}{$\begin{array}{c}\text { Pastizales, eriales a } \\
\text { montes y montes claros: } \\
\quad 14.000(84,14 €)\end{array}$} \\
\hline Del anexo 3 & 282.000 & $1.694,85$ & 40.000 & 240,4 & \\
\hline De crecimiento rápido & 120.000 & 721,21 & 一 & - & \\
\hline
\end{tabular}

Fuente: Decreto 127/1998 de 20 de junio. BOJA n ${ }^{\circ} 68$.

Nota: Las primas de Reforestación recogidas corresponden a los Titulares individuales; las primas

Compensatorias a los agricultores ATP, siendo las demás más bajas.

Especies del anexo 1: Especies arbóreas cuya plantación tenga como fin principal la producción de madera un plazo mayor de 18 años (coníferas).

Especies del anexo 2: especies arbóreas cuya plantación tenga como fin principal la restauración o creación de ecosistemas permanentes (mayoritariamente frondosas).

Especies del anexo 3 :Especies arbórea y arbustivas autóctonas de interés particular en ciertas zonas por motivos de producción de maderas valiosas, endemismos en peligro de extinción (incluye hendirnos, madroños, acebos, nogales, sabinas, abedules, tejos...)

Especies de crecimiento rápido: especies arbóreas cuya producción tenga como fin principal la producción de madera en un plazo menor de 18 años (chopos y eucaliptus).

En el cuadro anterior hemos recogido el caso de un agricultor individual que decida acogerse al programa, pero si las solicitudes son presentadas por asociaciones de agricultores el importe de la prima se incrementa entre un dos y un cinco por ciento; en cambio con la anterior normativa el incremento llegaba al $10 \%$. 
Se han establecido tres tipos de primas:

$1^{\circ}$.- La Prima de Reforestación es muy distinta dependiendo del tipo de especies utilizadas, de forma que se bonifica más a las especies autóctonas (frondosas) y a las que producen maderas valiosas o son endemismos en vías de desaparición, que a las coníferas y a las de crecimiento rápido foráneas, como los eucaliptos, que son las menos subvencionadas. Esto supone un cambio radical con respecto a las anteriores políticas forestales estatales, preocupados desde los años cuarenta por producir madera abundante y barata con especies de ciclo lo más corto posible. Así, entre las ayudas a las especies de crecimiento rápido ( 120.000 pts. $=721,2$ euros) y las del anexo 3 (282.000 Ptas. $=1.694,8$ euros), que son 2,35 veces más elevadas en su cuantía, los agricultores tenderán a utilizar especies mejor subvencionadas, cambiándose de esta forma la orientación productivista predominante hasta ahora en la política forestal.

Además es muy positivo también que se permita la mezcla de especies que es la forma más aconsejada por los técnicos para que la repoblación sea un éxito, incrementándose la prima a medida que se aumenta el porcentaje de especies de los anexos 2 y 3 en las plantaciones.

Esta nueva política repobladora ha cambiado las pautas vigentes en España desde los años cuarenta, época en la que las repoblaciones se hicieron con fines exclusivamente industrial-productivistas. "El criterio orientativo que predominó por completo en la toma de decisiones forestales fue el de producir grandes cantidades de madera barata en plantaciones del ciclo más corto posible" (GROOME, H., 1990, 93). Esta política productivista empieza a cambiar algo con la creación del ICONA en 1971, un organismo supuestamente conservacionista, que pretendía introducir conceptos y criterios medioambientales en la política forestal pero sin olvidar la orientación productivista, es decir la producción de madera, como comprobamos al constatar que las repoblaciones realizadas durante estos años con especies autóctonas no llegaron a representar el 1\% del total (GROOME, H., 1990, 175); es decir, de hecho predominaron las coníferas y las especies de crecimiento rápido, marginando a las especies autóctonas de crecimiento lento.

La cuantía de la Prima de Reforestación varía también en función de la pendiente media de la superficie a reforestar y en función de la dificultad de laboreo. En el primer caso cuando la pendiente media es inferior al 5\% la prima se reduce en un $25 \%$ y se incrementará en un 10\% cuando la pendiente esté entre el 5-20\% y en un $15 \%$ cuando supere el $20 \%$ de pendiente. Según la dificultad de laboreo se incrementarán en un 5 o un $10 \%$ el valor de las primas cuando exista una dificultad media $\mathrm{y}$ alta respectivamente.

$2^{\circ}$.- La Prima de Mantenimiento es distinta, dependiendo del tipo de especies utilizadas en la repoblación; los agricultores que reforesten con las del anexo 2 y 3 reciben la máxima cuantía, 40.000 ptas (240,4 euros); en cambio, los que repoblen 
con coníferas recibirán una prima mucho más reducida, de 25.000 ptas. (150 euros). Tendrá cinco años de duración y esta prima no la percibirán las reforestaciones que utilicen especies de crecimiento rápido.

$3^{\circ}$.- La Prima Compensatoria es muy distinta según la solicite un agricultor a título principal (ATP) o un agricultor que no cumpla estos requisitos (No ATP). En el primer caso, que es el que hemos recogido en el cuadro recibirá entre un 33\% y $42,8 \%$ más dependiendo del tipo de cultivos que abandone. La prima máxima que puede recibirse asciende a 4 millones de ptas, incrementadas en un $20 \%$ en caso de ser ATP. En definitiva, lo que pretende la normativa es potenciar con ayudas más elevadas a los agricultores que viven del trabajo en sus tierras de las que obtienen la mayor parte de su renta; en cambio, los que tienen en la agricultura un complemento de renta reciben ayudas sensiblemente inferiores, puesto que su renta final no se va a ver tan afectada por el cambio de uso de sus tierras. Esta prima tiene una duración de veinte años, destinada a compensar la pérdida de renta que supone el abandono del anterior aprovechamiento agrario, y que no percibirán tampoco los propietarios que reforesten con especies de crecimiento rápido.

Otro aspecto novedoso a tener en cuenta a la hora de recibir la subvención es la utilización de plantas micorrizadas o inoculadas, siempre que esté justificado el uso de las mismas y así lo recomiende el informe del técnico de la Consejería de Agricultura y Pesca, lo que repercutirá en un incremento del 5\% en las primas.

Dadas las características de la superficie granadina con un elevado porcentaje de tierras en pendientes elevadas por la presencia de complejos montañosos muy relevantes tanto por su extensión superficial como por la enorme variabilidad geomorfológica y altitudinal (RODRÍGUEZ, F., 1984) podemos avanzar que hay un volumen importante de tierras agrarias que pueden acogerse a este programa pues un 50\% de la superficie provincial está incluida entre los 800-1200 m de altitud y una cuarta parte de la superficie provincial tiene una altitud media superior a los $1200 \mathrm{~m}$. "debido a la existencia de cordilleras y, en especial, de su principal conjunto montañoso, Sierra Nevada, con las cimas más altas de la Península Ibérica" (BOSQUE, J.; FERRER, A., 2000, 41).

Las cuantías de las Primas establecidas consideramos que son bastante atractivas para los agricultores ATP, algo menos para los No ATP, que si además poseen propiedades con características de pendiente y dificultad de laboreo grandes, hecho bastante frecuente en nuestra provincia que está atravesada por las cimas más importantes del sistema penibético por el sur y del subbético en el noreste, verán cómo se incrementan sustancialmente las ayudas percibidas.

A efectos de cálculo incluimos las primas que conseguiría un ATP por reforestar 20 has. dedicadas a cultivos herbáceos, que son los que más prima compensatoria reciben, con especies del anexo 2 , en pendientes superiores al $5 \%$ y dificultad media 
para el laboreo; en total recibiría una subvención durante los 20 años de 24,865 millones de ptas. (14.944,16 euros). Los cálculos son los siguientes.

a) Prima de reforestación: 255.000 ptas/Ha x 20 Has $=5.100 .000$ ) más un 15\% por las dificultades añadidas de pendiente y laboreo 38.250 ptas/Ha x $20=765.000$ (4.597,6 euros).

b) Prima de mantenimiento: $40.000 \times 20 \mathrm{Ha}=800.000 \times 5$ años $=4.000 .000$ (24.040 euros).

c) Prima compensatoria: $37.500 \times 20 \mathrm{Ha}=750.000 \times 20$ años $=15.000 .000(90.151,8$ euros).

Los incentivos económicos ofertados parecen ser lo suficientemente atractivos para conseguir que los titulares de propiedades cambien sus cultivos y se decidan a participar en el proceso reforestador, y lo han hecho, pero quizás no en la cantidad esperada por los problemas que ha generado la plantación en años de acusada sequía y las mediciones de las tierras forestadas por el sistema GPS y por la falta de recursos económicos. Precisamente el objetivo del presente artículo es poner de manifiesto la repercusión que este programa ha tenido en nuestra provincia, que analizamos en el apartado siguiente.

Se establecen, además, ayudas para la diversificación del paisaje, con un máximo de superficie equivalente de 10 has por beneficiario y año, son las siguientes:

1) Plantaciones lineales, con un máximo de 3000 plantas, en marcos de plantación entre 2 y 3 metros, siendo la ayuda resultante calculada dividiendo el número de plantas por la densidad mínima exigida según la especie utilizada que establecen los Anexos 1, 2 y 3 del Decreto. (Si se trata de encinas la densidad mínima es de 300 pies, pero en caso de utilizar Pino carrasco, laricio o silvestre la densidad mínima es de 700 pies/Ha)

2) Creación de setos vivos, con un máximo de 2000 plantas en marcos de plantación entre 1 y $2 \mathrm{~m}$ de distancia, con igual sistema de cálculo para la ayuda que en el caso anterior.

3) Plantaciones de enriquecimiento, densificación o por bosquetes en montes claros con un máximo de 3000 plantas en una superficie inferior a las 20 ha.

El programa se completa con la concesión de ayudas para la realización de nuevos cortafuegos (45.000 ptas/Ha $=270,46$ euros) y con una ayuda por punto de agua con capacidad igual o superior a 50 metros cúbicos de 100.000 ptas. (601 euros) que podrán ascender a 200.000 (1.202 euros) en caso de construir depósitos de hormigón cerrado en caso de existir un manantial de agua o un arroyo. 
Las ayudas están condicionadas al cumplimiento de una serie de condiciones técnicas, sanitarias y de densidad de arbolado mínimo por ha. según el tipo de especie utilizado. Así, se establece que las plantas procedentes de viveros comerciales deberán venir provistas de pasaporte fitosanitario y las semillas y plantas empleadas serán de calidad genética garantizada. Otra de las condiciones técnicas es que las especies elegidas deben estar adaptadas al tipo de suelo, a la altitud y a las condiciones climatológicas y geográficas de la zona en cuestión. Otra de las condiciones técnicas previstas y que está ocasionando problemas a los titulares de explotaciones acogidos al programa para poder recibir la subvención es la medición final mediante levantamiento topográfico o mediante Sistema de Posicionamiento Global (GPS) firmada por un técnico competente y visada por el Colegio Oficial. A través del servicio de control de la Consejería de Agricultura hemos podido conocer que existen bastantes casos de diferencias notables entre la superficie inicialmente declarada y la que finalmente establece el mencionado procedimiento técnico, lo que obliga a reintegrar las cantidades percibidas en exceso, incrementadas por los intereses de demora desde el momento del pago.

Desde entonces y hasta fecha reciente se han producido cambios en la gestión de las ayudas motivados por la experiencia y los errores cometidos, por lo que la administración central ha publicado un nuevo Decreto 6/2001 de 12 de enero que actualiza las ayudas en consonancia con los cambios producidos en la política comunitaria. Desde esta fecha se espera que la Consejería de Agricultura y Pesca publique un nuevo Decreto que actualice las ayudas, sin embargo aún no se ha producido esta adaptación, que según los técnicos obedece a una falta de recursos para continuar con el programa, que desde 1998 languidece, no habiéndose admitido nuevas solicitudes de reforestación. El nuevo Decreto está aún pendiente de salir lo que está suponiendo un lamentable retraso con respecto al resto de España, retraso que en el momento de redactar este artículo (junio de 2004), ya es de 41 meses.

Las ayudas establecidas han sido las siguientes:

- Ayudas destinadas a compensar los gastos de forestación

- Primas destinadas a gastos de mantenimiento y reposición de marras

- Primas destinadas a compensar la pérdida de ingresos derivados de la forestación de tierras agrícolas

- Ayudas destinadas a favorecer inversiones para mejorar o renovar plantaciones existentes.

Entre otros aspectos este nuevo Real Decreto ha incrementado las ayudas a los costes de plantación hasta un máximo de 426.000 ptas/Ha (2.560,3 euros) para las frondosas de crecimiento lento, las ayudas a los costes de mantenimiento hasta 48.000 (288,49 euros) y las ayudas compensatorias hasta 54.000 ptas (324,55 euros) para 
frondosas plantadas en masa pura en tierras dedicadas hasta entonces a cultivos herbáceos, leñosos y huertos familiares. Para poder beneficiarse de estas ayudas el Real Decreto establece que el agricultor que las solicite debe acreditar que obtiene el $15 \%$ de su renta de esta actividad y que le dedica, al menos, un $25 \%$ de su tiempo. Ahora corresponde a la Consejería de Agricultura de la Junta de Andalucía la adaptación del mismo a nuestra Comunidad. Pero como su análisis no afecta al objetivo de este artículo que es analizar la influencia del programa de reforestación de tierras agrarias en la década de los noventa en Granada cerraremos aquí el análisis de la reglamentación oficial, no sin antes recordar que desde 1998 existen dos líneas de ayudas al bosque que comentamos.

Hasta 1998 la Consejería de Agricultura ha sido la encargada de la gestión de las ayudas del subprograma 1 (gastos de forestación, primas de mantenimiento y compensación de rentas, mejoras en alcornocales y otras infraestructuras), pero a partir de 1998 se hace responsable a la Consejería de Medio Ambiente de estas últimas, permaneciendo en la Consejería de Agricultura las primeras, es decir la forestación de tierras agrarias.

La segunda línea de ayudas al bosque, subprograma 2, son las financiadas por la Consejería de Medio Ambiente a través del "Régimen de ayudas para el fomento de Acciones de Desarrollo y Aprovechamiento de los Montes de las zonas rurales de Andalucía" puestas en funcionamiento en virtud de las determinaciones del Reglamento (CE) 1.257/1999 del Consejo de 17 de mayo, sobre la ayuda al desarrollo rural a cargo del FEOGA, programa regulado en Andalucía mediante el Decreto 280/2001 de 26 de diciembre (BOJA $n^{\circ} 149$ ), por el que se establecen las ayudas de la Junta a los sectores agrícola, ganadero y forestal incluidas en el Programa Operativo Integrado Regional de Andalucía para el Desarrollo del Marco Comunitario de Apoyo del periodo 2000-2006. Ha sido completado y desarrollado en la Orden de 9 de mayo de 2002 por la que establecen las bases reguladoras de la concesión de ayudas para la gestión sostenible de los recursos forestales, previstas en el Decreto antes mencionado (INFORME 2001. MEDIO AMBIENTE EN ANDALUCÍA, 209).

\section{REPERCUSIONES DEL PROGRAMA COMUNITARIOENLA PROVINCIA DE GRANADA}

\subsection{Superficie reforestada por particulares y especies utilizadas}

Los resultados de la aplicación del programa europeo de reforestación en la provincia de Granada, realizadas al amparo de lo establecido en el Decreto 73/1993, ascienden a 14.435 has. en seis años, resultando una media de casi 2.405 por año, 
cuando en Andalucía la media por año es de 29.908, habiéndose reforestado una superficie de $179.447 \mathrm{Ha}$. (cuadro 7). El incremento porcentual en Granada ha sido del 4,96\%, mientras que en Andalucía el porcentaje ha sido del 7,58\%; es decir dos puntos y medio más bajo en Granada que en Andalucía. La realidad indica que el Plan de Reforestación no se ha cumplido en su totalidad pues de las 250.000 has. previstas en él sólo se han reforestado 179.447, un 71,7 \% de lo previsto.

\section{CUADRO 7. \\ AYUDAS A LAS INVERSIONES FORESTALES PRIVADAS EN EXPLOTACIONES AGRARIAS. (DECRETO 73/1993) EN LA PROVINCIA DE GRANADA Y EN ANDALUCÍA (1993-98)}

\begin{tabular}{|c|c|c|c|c|}
\hline \multirow{2}{*}{ Años } & \multirow{2}{*}{$\begin{array}{c}\text { Solicitudes } \\
\text { aprobadas }\end{array}$} & \multirow{2}{*}{ Hectáreas } & \multicolumn{2}{|c|}{ Ayudas } \\
\hline & & & Pesetas & Euros \\
\hline \multicolumn{5}{|c|}{ GRANADA } \\
\hline 1993 & 68 & $1.810,82$ & 482.820 .000 & $2.901 .806,60$ \\
\hline 1994 & 197 & $5.387,43$ & 1.250 .071 .000 & 7.513.078,00 \\
\hline 1995 & 58 & $1.460,65$ & 437.596 .000 & $2.642 .025,10$ \\
\hline 1996 & 77 & $2.008,84$ & 472.524 .000 & $2.839 .926,40$ \\
\hline 1997 & 91 & $2.291,31$ & 548.364 .000 & $3.295 .734,00$ \\
\hline 1998 & 50 & $1.475,98$ & 414.730 .000 & $2.492 .577,50$ \\
\hline TOTAL & 541 & $14.435,03$ & 3.606 .105 .000 & $21.673127,50$ \\
\hline \multicolumn{5}{|c|}{ ANDALUCÍA } \\
\hline 1993 & 391 & $10.362,00$ & 2.578.912.000 & $15.499 .573,28$ \\
\hline 1994 & 1.193 & $37.382,10$ & 11.047 .449 .000 & $66.396 .505,71$ \\
\hline 1995 & 924 & $34.046,50$ & 10.529 .310 .000 & $63.282 .427,60$ \\
\hline 1996 & 1.196 & $37.765,10$ & 10.988 .523 .000 & $66.042 .353,32$ \\
\hline 1997 & 1.218 & $34.561,70$ & 9.424 .057 .000 & $56.639 .723,29$ \\
\hline 1998 & 687 & $25.336,00$ & 7.069.731.000 & $42.489 .939,06$ \\
\hline TOTAL & 5.609 & $179.453,40$ & 51.637 .982 .000 & $310.350 .522,26$ \\
\hline
\end{tabular}

Fuente: La agricultura y la Pesca en Andalucía. Memorias anuales. Elaboración propia. Nota: las ayudas finalizaron en el año 1998. 
En el cuadro anterior observamos cómo las ayudas solicitadas se concentraron en Granada en el año 94, con un total de 197 solicitudes y una superficie de 5.387 has. En el año 1995 se redujeron sustancialmente las solicitudes y la superficie forestada a menos de 1.500 has. , pero a partir de ese año estuvieron por encima de las 2.000 has., hasta que en el 98 vuelven a reducirse a 1.447. El año 99 ya no se aceptaron nuevas solicitudes por lo que el programa ha quedado paralizado por falta de fondos para su financiación y por los problemas surgidos, que hemos analizado más atrás. Y en el año 2000 las actuaciones realizadas en el programa de reforestación fueron la tramitación y pago, tanto de certificaciones de obras de 1998 (con plazo de ejecución hasta finales del 2000), como por primas de mantenimiento y compensatorias (MEMORIA 2000, 331)

\section{CUADRO 8.}

ESPECIES UTILIZADAS EN LA FORESTACIÓN DE TIERRAS AGRÍCOLAS EN LA PROVINCIA DE GRANADA (1993-1998)

(Decreto 73/93)

\begin{tabular}{|c|r|r|r|r|r|r|r|r|r|}
\hline Años & Encina & $\begin{array}{c}\text { Alcor- } \\
\text { nocal }\end{array}$ & $\begin{array}{r}\text { Ace- } \\
\text { buche }\end{array}$ & $\begin{array}{c}\text { Alga- } \\
\text { rrobo }\end{array}$ & $\begin{array}{c}\text { Pino } \\
\text { Carrasco }\end{array}$ & $\begin{array}{c}\text { Pino } \\
\text { Piñonero }\end{array}$ & Nogal & Resto (*) & TOTAL \\
\hline 1993 & $1.189,9$ & 3,6 & 8,1 & 0,0 & 270,8 & 21,3 & 140,3 & 176,1 & $1.810,1$ \\
\hline 1994 & $2.257,5$ & 0,9 & 53,4 & 4,2 & $1.853,7$ & 26,2 & 427,2 & 764,7 & $5.387,7$ \\
\hline 1995 & 741,5 & 0 & 39,0 & 34,1 & 446,0 & 10,6 & 125,8 & 63,4 & $1.460,47$ \\
\hline 1996 & \multicolumn{10}{|c|}{ No viene la información por provincias } \\
\hline 1997 & No viene la información por provincias \\
\hline 1998 & No viene la información por provincias \\
\hline TOTAL & $4.188,9$ & 4,5 & 100,5 & 38,3 & $2.570,5$ & 58,1 & 693,3 & $1.004,2$ & $8.658,27$ \\
\hline
\end{tabular}

Fuente. La agricultura y la Pesca en Andalucía. Memorias Anuales.

(*) En 1994 corresponden 488,7 has. a cerezos silvestres y 93 has. en 1993.

Nota: las ayudas finalizaron en el año 1998

Si analizamos el tipo de especies utilizadas en las repoblación recogidas en el cuadro 8, con información para sólo tres años, deducimos que la encina es el árbol más utilizado, seguida del pino carrasco y del nogal. Es lógico que así sea ya que el factor predominante a la hora de elegir la especie es el económico, aunque en este caso también coincida con el ecológico, pues la encina es la especie autóctona por excelencia; sin embargo, los técnicos aconsejan una mezcla de pino y encina 
para facilitar el cuajo y crecimiento de las encinas, porque según los especialistas, ingenieros de montes, "las coníferas y en especial los pinos son organismos especializados en llenar los espacios vacíos que no ocupan otros árboles mucho más exigentes, para soportar la sequía impuesta por un período árido, en particular sobre suelos incapaces de retener agua... El criterio que debe prevalecer, en el momento de elegir las especies a emplear para la restauración de la cubierta vegetal, es el de ser capaces de sobrevivir en suelos arruinados y sometidos a las perturbaciones propias de climas fluctuantes y con amplios contrastes..." (GORDO y GIL, 1991, 93).

Las ayudas por la vía del Decreto73/1993 no han agotado las posibilidades de reforestación en la provincia, sino que además las administraciones públicas han continuado con sus programas específicos para incrementar la masa forestal arbolada. Para su análisis a fin de conocer el saldo real de has. reforestadas en la última década incluimos los dos cuadros siguientes, el primero recoge los datos pormenorizados correspondientes a la provincia de Granada y el segundo los de Andalucía.

\subsection{Superficie reforestada por las Administraciones públicas y especies utilizadas} (Cuadros 9 y 10)

Durante la década de los noventa las administraciones repoblaron en Granada 20.807 has, de ellas más de las tres cuartas partes, el 79\%, con coníferas y el resto con frondosas; es decir casi a la inversa que ha ocurrido en el programa de reforestación auspiciado por la UE, que ha exigido el uso de especies autóctonas para repoblar y en concreto las frondosas antes que las coníferas. En Andalucía el total de has. asciende a 97.691,4 de ellas el 59,2\% son de coníferas y el 40,8\% de frondosas. En definitiva, que las administraciones públicas continúan aún dando prioridad a la producción maderera a la hora de repoblar, en clara contradicción con lo exigido a los particulares.

El ritmo repoblador ha resultado desigual pues en Andalucía el año de mayor superficie repoblada fue 1997 con 25.227 has.; en cambio en Granada fue el año 1992 con 4.685. En 1999 se produce un fuerte descenso de las repoblaciones forestales públicas, coincidiendo con el aplazamiento sine die del programa de reforestación auspiciado por la nueva PAC para los agricultores interesados en cambiar el uso de sus tierras, parón que se ha prolongado al menos dos años más, lo que pone de manifiesto la escasa dotación presupuestaria disponible y, por tanto, el escaso interés de las administraciones en continuar un serio y riguroso programa de reforestación que sigue siendo muy necesario para que nuestros bosques continúen incrementado la superficie total. 


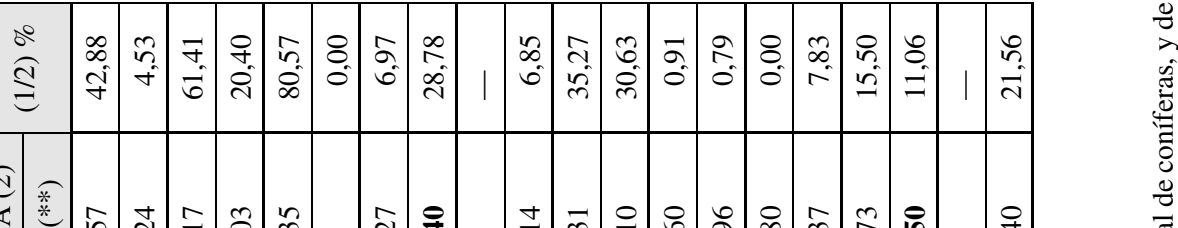

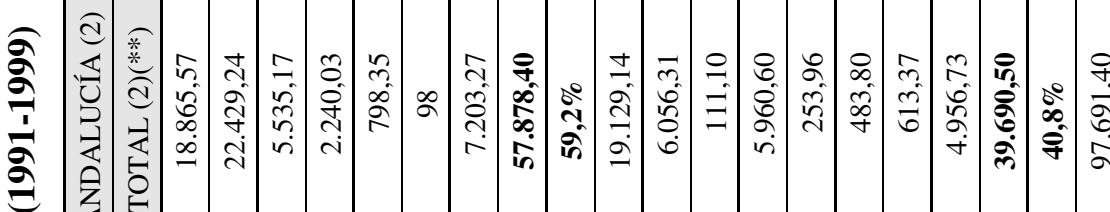

퓽

ㅁ․․

卷若

。응

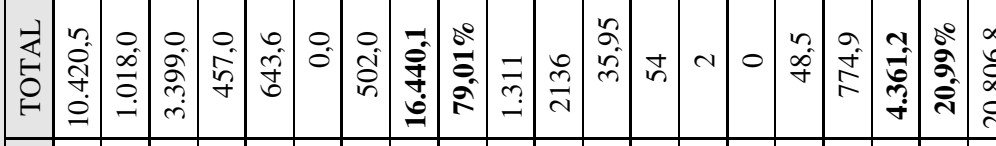

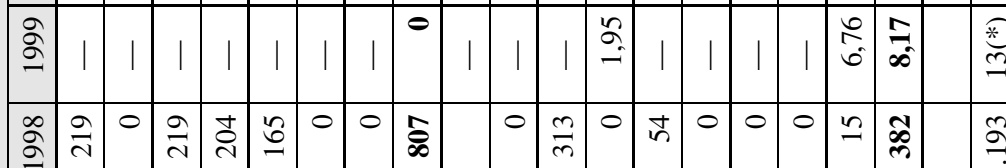

苋

远

\&

节 $\frac{0}{0}$

$\approx$ 임

जี ลे ร

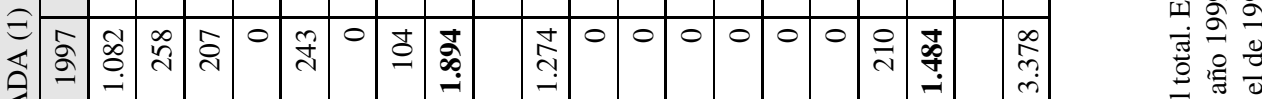

$\vec{\nabla} \frac{\overline{0}}{0}$

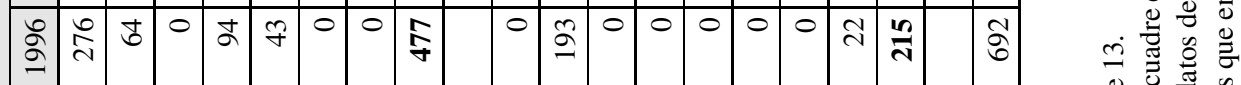

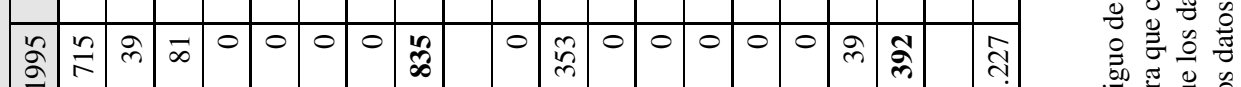

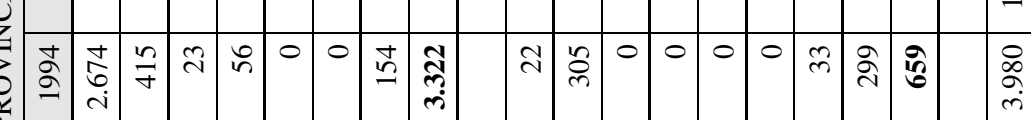

.

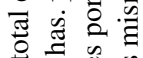

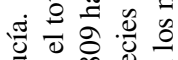

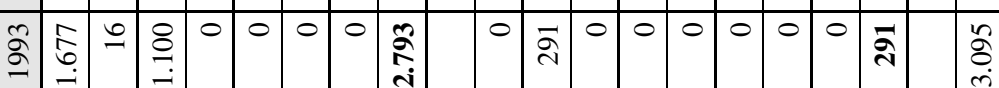

琎 \& $\cong$ i 0

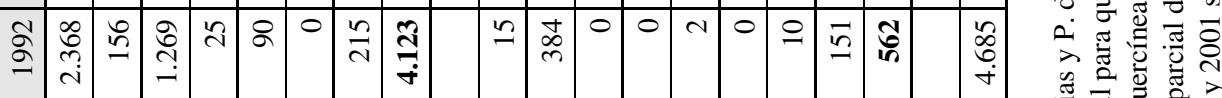

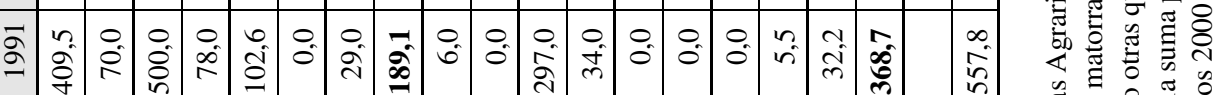

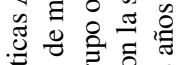
谞 䒕

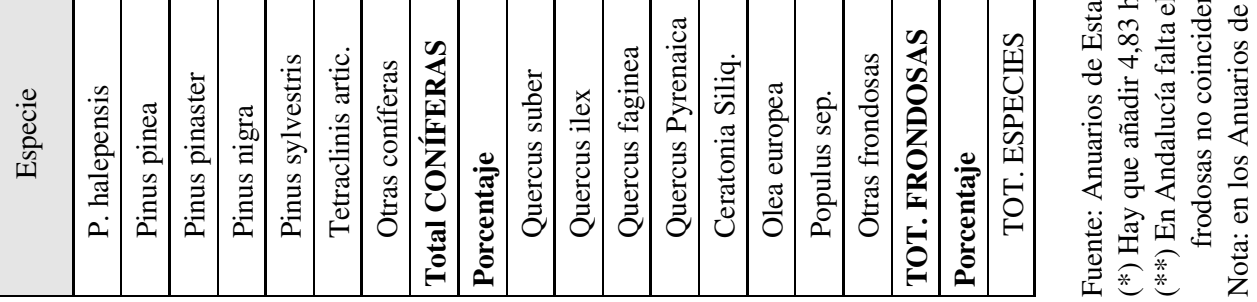


La forestación de tierras agrícolas en la provincia de Granada. Acciones dentro...

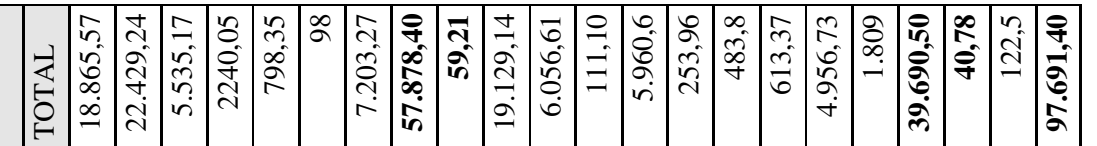

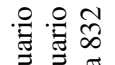
安莨苧

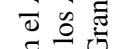
ฮี 데

ลे

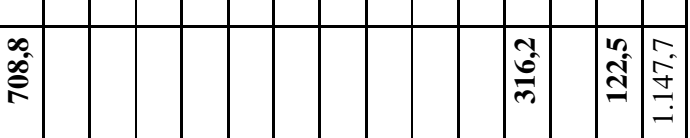

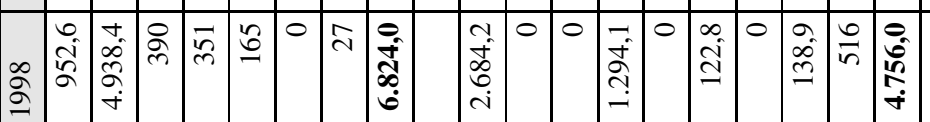

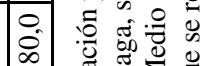

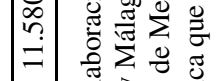

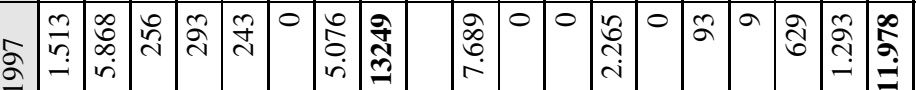

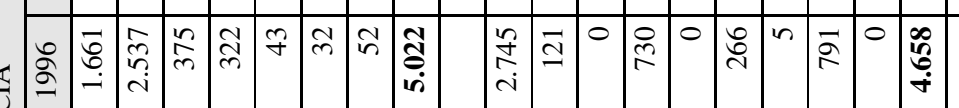
피료 $>0$ तิ

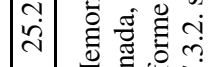
刍结

$\therefore$,

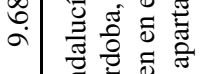

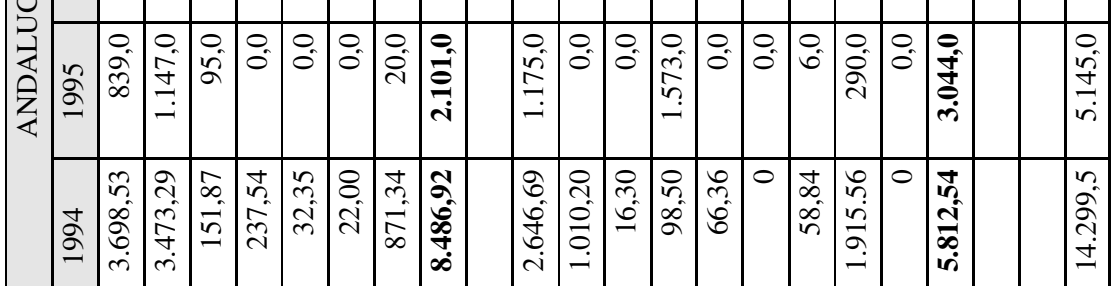

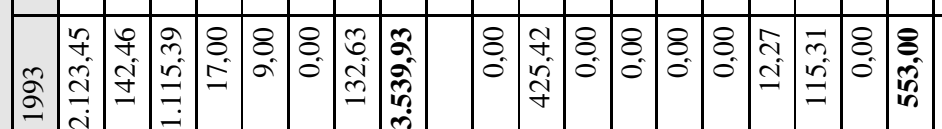

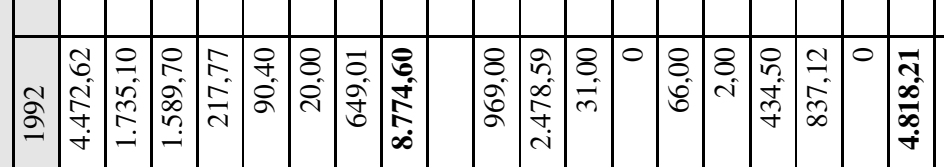
ㅇ. กิร

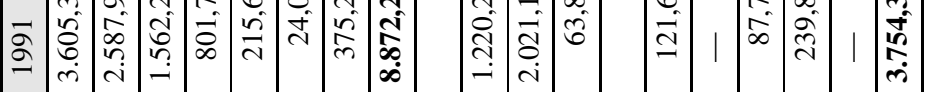

ป ब

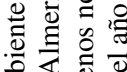
娄范

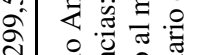

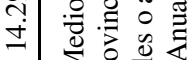
$\sum_{\lambda} \frac{1}{2} \frac{\pi}{\pi}$

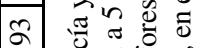

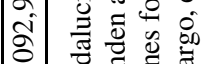

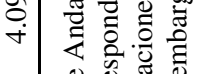
웜유.

i

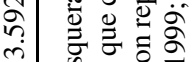
2. 웡 ते है है กิ i. हे छ :

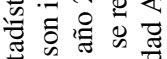

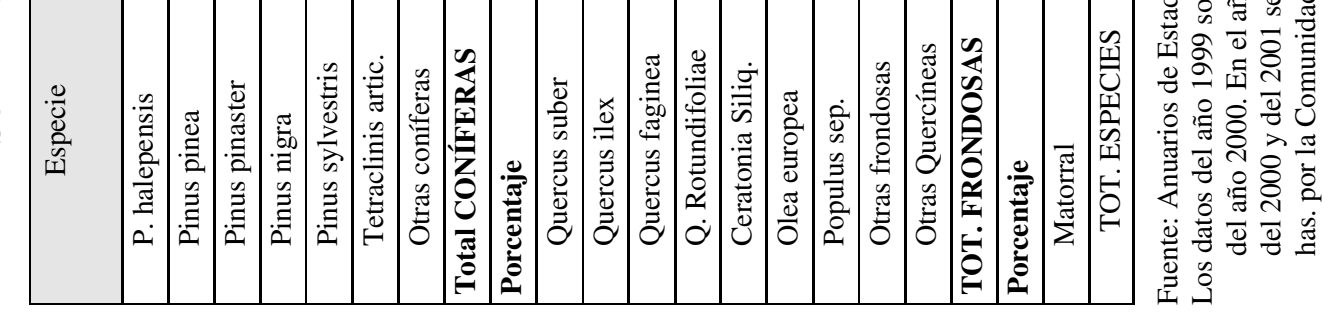




\section{LOS INCENDIOS FORESTALES EN ANDALUCÍA Y GRANADA}

Un problema grave que afecta todos los años al monte es la pérdida de masa forestal por culpa de los incendios que se producen en la estación seca preferentemente.

Según PÉREZ VILARIÑO, los bosques arden porque pueden arder y porque no son rentables, debido al abandono, la descapitalización y a la alta conflictividad social existente, en consecuencia dejarán de arder cuando aparezcan como económicamente rentables y socialmente útiles (PÉREZ VILARIÑO, 1998, 29) (Cuadro 11).

\section{CUADRO 11.}

LOS INCENDIOS FORESTALES EN LA PROVINCIA DE GRANADA, SUPERFICIE QUEMADA (1991-2002)

\begin{tabular}{|c|c|c|c|c|c|c|c|}
\hline \multirow[b]{2}{*}{ AÑO } & \multirow{2}{*}{$\begin{array}{l}\text { Número } \\
\text { Incendios }\end{array}$} & \multirow{2}{*}{$\begin{array}{c}\text { Superficie } \\
\text { Desarbolada }\end{array}$} & \multirow{2}{*}{$\begin{array}{l}\text { Superficie } \\
\text { Arbolada }\end{array}$} & \multicolumn{2}{|c|}{ Granada } & \multicolumn{2}{|c|}{ Andalucía } \\
\hline & & & & $\begin{array}{c}\text { Sup. } \\
\text { Quemada }\end{array}$ & $\begin{array}{l}\% \text { Sup. } \\
\text { Forestal }\end{array}$ & $\begin{array}{c}\text { Sup. } \\
\text { Quemada }\end{array}$ & $\begin{array}{l}\text { \% Sup. } \\
\text { Forestal }\end{array}$ \\
\hline 1991 & 232 & 1.114 & 466 & 1.580 & 0,56 & 67.578 & 2,55 \\
\hline 1992 & 161 & 669 & 101 & 770 & 0,27 & 16.850 & 0,64 \\
\hline 1993 & 122 & 1.190 & 6.508 & 7.698 & 2,71 & 17.701 & 0,75 \\
\hline 1994 & 65 & 3.009 & 5.373 & 8.382 & 2,94 & 28.696 & 1,08 \\
\hline 1995 & 139 & 237 & 168 & 405 & 0,14 & 11.777 & 0,44 \\
\hline 1996 & 48 & 16 & 36 & 52 & 0,00 & 892 & 0,03 \\
\hline 1997 & 90 & 75 & 282 & 357 & 0,12 & 2.459 & 0,09 \\
\hline 1998 & 144 & 519 & 91 & 610 & 0,21 & 3.589 & 0,14 \\
\hline 1999 & 114 & 1.222 & 1.405 & 2.627 & 0,90 & 6.088 & 0,23 \\
\hline 2000 & 95 & 510 & 799 & 1.309 & 0,45 & 3.748 & 0,15 \\
\hline 2001 & 140 & 524 & 237 & 761 & 0,26 & 6.015 & 0,23 \\
\hline 2002 & 169 & 1.744 & 212 & 1.956 & 0,67 & 6.174 & 0,24 \\
\hline TOTAL & 1519 & 10.829 & 15.678 & 26.507 & 9,09 & 171.567 & 6,66 \\
\hline
\end{tabular}

Fuente: Anuarios de Estadísticas Agrarias y Pesqueras de Andalucía. Medio Ambiente en Andalucía. Informe, 2002. Elaboración propia.

La superficie arbolada quemada entre el año 1991 y el año 2002 asciende a 15.678 has. prácticamente la misma cantidad que había sido reforestada por los 
particulares en los seis años de aplicación del programa, por lo que la superficie forestal real se ha incrementado en la cantidad reforestada por las administraciones públicas. Además han sido pasto de las llamas 10.829 has. de superficie desarbolada de monte bajo y matorral. Porcentualmente se ha quemado el $9,1 \%$ del terreno forestal de Granada, tomando como superficie de referencia la total final de la serie, y en torno al 6,7\% en Andalucía; dos puntos y medio de diferencia entre ambos guarismos, que pone de manifiesto que en Granada la incidencia de los incendios es más alta (Cuadro 12).

\section{CUADRO 12.}

\section{CAUSAS DE LOS INCENDIOS FORESTALES, AÑOS 2000 Y 2002}

\begin{tabular}{|l|r|r|r|r|r|r|r|r|r|r|r|r|}
\cline { 2 - 13 } \multicolumn{1}{c|}{} & \multicolumn{2}{c|}{$\begin{array}{c}\text { Intencio- } \\
\text { nados }\end{array}$} & \multicolumn{2}{c|}{$\begin{array}{c}\text { Negli- } \\
\text { gencias }\end{array}$} & \multicolumn{2}{c|}{ Naturales } & \multicolumn{2}{c|}{$\begin{array}{c}\text { Acciden- } \\
\text { tales }\end{array}$} & \multicolumn{2}{c|}{$\begin{array}{c}\text { Desco- } \\
\text { nocidos }\end{array}$} & \multicolumn{2}{c|}{ Total } \\
\cline { 2 - 14 } \multicolumn{2}{c|}{2000} & 2002 & 2000 & 2002 & 2000 & 2002 & 2000 & 2002 & 2000 & 2002 & 2000 & 2002 \\
\hline Granada & 31 & 44 & 42 & 61 & 4 & 6 & 8 & 15 & 10 & 43 & 95 & 169 \\
\hline Andalucía & 387 & 378 & 310 & 379 & 13 & 40 & 87 & 141 & 130 & 237 & 927 & 1.175 \\
\hline
\end{tabular}

Fuente: Anuarios de Estadísticas Agrarias y Pesqueras de Andalucía. Elaboración propia.

Las causas de los incendios, tomando como referencia el año 2000, en el que se produjeron 95 incendios, son: las negligencias a la hora de realizar labores agrícolas o de otro tipo (42 casos), intencionados (31 casos), desconocidos (10), accidentales (8) y naturales (4). Durante el año 2002 se produjeron 169 incendios, un 77,8\% más que en el año 2000, siendo de nuevo las negligencias humanas, con 61 casos, y los intencionados, con 44, las causas más significativas. En definitiva, que la acción humana, tanto voluntariamente como involuntariamente, ha producido la mayoría de los incendios, el 76,8\% y $62 \%$ respectivamente. Ante esta alarmante situación hemos de exigir un mayor control y vigilancia a las administraciones públicas y al resto de la población una mayor colaboración. Respecto a los intencionados deben analizarse las causas (económicas, urbanísticas, madereras, ganaderas...) que inducen a los pirómanos a quemar para tratar de darles solución.

Por especies, los incendios producidos en el periodo 1994-2001 han afectado más al matorral $(35,8 \%)$, seguido de las coníferas $(22,2 \%)$ y de las encinas $(16,7 \%)$ (INFORME, 2.001. MEDIO AMBIENTE EN ANDALUCÍA, 430).

Además, los incendios permiten conocer el incremento real de superficie boscosa al descontar a las repoblaciones realizadas las hectáreas quemadas como consecuencia de los mismos. En el cuadro siguiente incluimos estas cifras. 
CUADRO 13.

INCREMENTO REAL DE LA SUPERFICIE FORESTAL EN GRANADA, 1991-2001

\begin{tabular}{|c|c|c|c|c|c|c|}
\cline { 2 - 7 } \multicolumn{1}{c|}{} & $\begin{array}{c}\text { Sup. } \\
\text { Forestada } \\
\text { Adm. Públicas }\end{array}$ & $\begin{array}{c}\text { Sup. } \\
\text { Forestada } \\
\text { Particulares }\end{array}$ & $\begin{array}{c}\text { Sup. } \\
\text { Forestada } \\
\text { Total (A) }\end{array}$ & $\begin{array}{c}\text { Sup. } \\
\text { Arbolada } \\
\text { quemada (B) }\end{array}$ & $\begin{array}{c}\text { Saldo } \\
(\text { A-B) }\end{array}$ & $\begin{array}{c}\text { \% Incremen. } \\
\text { Sup. Forestal }\end{array}$ \\
\hline 1991 & 2.558 & 0 & 2.558 & 466 & 2.092 & 0,74 \\
\hline 1992 & 4.686 & 0 & 4.686 & 101 & 4.585 & 1,62 \\
\hline 1993 & 3.095 & 1.811 & 4.906 & 6.508 & -1.602 & $-0,56$ \\
\hline 1994 & 3.980 & 5.387 & 9.367 & 5.373 & 3.994 & 1,40 \\
\hline 1995 & 1.227 & 1.461 & 2.688 & 168 & 2.521 & 0,89 \\
\hline 1996 & 692 & 2.009 & 2.701 & 36 & 2.665 & 0,93 \\
\hline 1997 & 3.378 & 2.291 & 5.669 & 282 & 5.387 & 1,86 \\
\hline 1998 & 1.195 & 1.476 & 2.671 & 91 & 2.580 & 0,89 \\
\hline 1999 & 13 & 0 & 13 & 1405 & -1.392 & $-0,52$ \\
\hline 2000 & 13 & 0 & 13 & 799 & -786 & $-0,27$ \\
\hline 2001 & 832 & 0 & 832 & 237 & 595 & 0,24 \\
\hline Total & 21.669 & 14.435 & 36.104 & 15.466 & 20.639 & 8,22 \\
\hline
\end{tabular}

Fuente: Anuarios de Estadísticas Agrarias y Pesqueras de Andalucía. Elaboración propia.

El incremento real de superficie boscosa granadina en la década de los noventa asciende a 20.639 has. a razón de unas 1.900 anuales. En conjunto la superficie boscosa provincial se ha incrementado un $8,2 \%$ tomando como referencia la superficie que existía en 1991.

Según los datos de las Cámaras Agrarias, los únicos disponibles a nivel municipal, la superficie de bosque en la provincia de Granada ascendía a 280.100 has. en 1997. La comarca con más presencia de superficie forestal es la de Baza con 91.313 has., que representan un tercio de la superficie provincial forestal, seguida de la comarca o Vega de Granada con un 12,97\%. Las áreas de los Montes y de las Alpujarras tienen el 10,66 y $10,62 \%$ respectivamente; mientras que las comarcas con menor presencia de bosques son las de Loja, 1,52\% y la de La Costa con un 4,76\%. 
CUADRO 14.

DISTRIBUCIÓN COMARCAL DE LA SUPERFICIE FORESTAL GRANADINA, 1997

\begin{tabular}{|c|r|r|r|r|r|}
\hline Comarca & M. Maderable & M. Abierto & M- Leñoso & TOTAL & \% Sup. Total \\
\hline Alhama & 6.650 & 5.781 & 4.777 & 17.208 & 6,14 \\
\hline Alpujarras & 17.231 & 6.068 & 6.437 & 29.736 & 10,62 \\
\hline Baza & 54.144 & 14.934 & 22.235 & 91.313 & 32,60 \\
\hline Costa & 8.486 & 0 & 4.847 & 13.333 & 4,76 \\
\hline Granada & 22.434 & 3.788 & 10.100 & 36.322 & 12,97 \\
\hline Guadix & 15.520 & 4.011 & 5.160 & 24.691 & 8,82 \\
\hline Lecrín & 14.237 & 137 & 390 & 14.764 & 5,27 \\
\hline Loja & 1.220 & 500 & 2.550 & 4.270 & 1,52 \\
\hline Marquesado & 15.585 & 1.520 & 1.497 & 18.602 & 6,64 \\
\hline Montes & 8.625 & 7.980 & 13.256 & 29.861 & 10,66 \\
\hline TOTAL & 164.132 & 44.719 & 71.249 & 280.100 & 100,00 \\
\hline
\end{tabular}

Fuente: Cámaras Agrarias Locales, 1997

\section{CONCLUSIONES}

El programa de reforestación ha obtenido unos resultados reducidos, pues se han repoblado en Granada 14.435 has. en 6 años, a razón de 2.406 al año, aunque la demanda ha sido bastante mayor, (de hecho sólo en 1993 se presentaron 1.323 solicitudes y una superficie a reforestar de 44.040 has, de las cuales fueron aprobadas 391 y una superficie de 10.362 has.) lo que pone de manifiesto la carencia de presupuesto para hacerle frente y las dificultades para llevar a cabo su gestión. En Andalucía se han repoblado en total 179.453 has. a razón de 29.908 al año, cantidad inferior a las 250.000 has. previstas en el Plan de Reforestación contenido en el Real Decreto 73/1993.

Este programa ha contribuido a reforzar el predominio del sector privado en los bosques granadinos y andaluces y ha incrementado la masa de especies de turno largo debido, no a una mayor conciencia ecológica entre los agricultores, sino a que las primas obtenidas son sensiblemente superiores si se utilizan especies de frondosas (encinas).

Hoy, paralizadas las ayudas desde 1998 y desaparecidos las subvenciones por problemas de diversa índole, que han quedado analizados en el texto, los particulares habrán perdido todo el interés acumulado por repoblar. 
Paralelamente las administraciones públicas han continuado con antiguos proyectos de reforestación y en Granada han conseguido reforestar 20.639 has. en el periodo analizado, a razón de 1.900 al año, ritmo inferior en 500 has. a las que han realizado los particulares.

En conjunto en esta década se han repoblado 35.242 has. de monte en Granada, que descontados las quemadas por incendios (15.466 has. de superficie arbolada), dejan un saldo de 20.639 has. (cuadro 13).

El programa de reforestación ha sido positivo, pero ha quedado corto, muy reducido en el tiempo y en los resultados, que han quedado por debajo de lo previsto, tanto por falta de medios económicos, pues la demanda ha superado con creces las disponibilidades económicas de la administración, como por los problemas surgidos en el proceso.

Desaparecidas estas ayudas, ha llegado el momento de buscar alternativas al bosque para hacerlo rentable a sus propietarios (mejores precios a sus subproductos, recuperación de antiguos aprovechamientos hoy en desuso, ayudas a los propietarios por los beneficios medioambientales que reportan).

Nos inclinamos por demandar un mayor apoyo público para mejorar e incrementar la superficie forestal provincial que tantos beneficios económicos y medioambientales reporta a la sociedad.

Y, en particular, es necesaria una Política Forestal Común que aúne esfuerzos para conseguir que Europa se autoabastezca de madera producida en nuestros montes y además contribuya a mejorar el medio ambiente y ponga a disposición de los ciudadanos mayores espacios para usos recreativos, cada vez más demandados por las sociedades urbanas. Es alentador constatar que cada vez hay una mayor preocupación por lo forestal en una etapa de crisis y agotamiento de las políticas rurales de base sectorial y eminentemente agraria, en una etapa en la que toca repensar lo rural en términos más territoriales, ambientales y de equilibrio de usos y aprovechamientos (FERNÁNDEZ, MATA, 2000, 483). A nivel europeo desde que se aprobó el "Futuro del Mundo Rural (1988), en la propia reforma de la PAC de 1992 y, sobre todo, en la Agenda 2000 se hacen continuas referencias a la necesidad de fomentar lo forestal, son, por tanto, buenos exponentes de los cambios que a nivel comunitario se están produciendo en el proyecto de ruralidad europeo.

No obstante, hay que reconocer que existen grandes dificultades para conseguirlo, como indica Helen GROOME: "Lograr la unificación de estas políticas es extremadamente difícil dados los diferentes intereses existentes no sólo entre los distintos países miembros de la CEE, sino también dentro de cada país" (GROOME, 1990, 270).

De hecho no ha existido una política forestal común en la CEE porque nunca interesó a los países fundadores, pese al déficit de madera que padecían, fue sólo a partir de la crisis de la Política Agraria Común debido al grave problema de los excedentes agrícolas cuando comenzó a surgir la necesidad doble, de por una parte reducir estos excedentes dejando a un volumen de tierras importante fuera del sistema 
productivo y en segundo lugar, la preocupación medioambiental, empieza a sentirse en Europa, lo que produjo que se añadiera al Tratado de Roma en 1985 un nuevo capítulo dedicado al medio ambiente, basado en los principios de que la protección del medio puede contribuir al crecimiento económico y a la creación de empleo en la Comunidad Europea y de que es necesaria una acción comunitaria en la protección de la atmósfera, el agua y el suelo y no acciones aisladas que pueden resultar ineficaces y hasta perjudiciales (GÓMEZ MENDOZA, 1992, 84)

\section{BIBLIOGRAFÍA Y FUENTES}

Anuarios de Estadística Agraria. MAPA. Madrid.

Anuario de Estadística Agroalimentaria, 2001. MAPA. Madrid.

Anuarios de Estadísticas Agrarias y Pesqueras. Junta de Andalucía. Consejería de Agricultura y Pesca.

BOSQUE, J.; FERRER, A. (1999): Granada, la tierra y sus hombres. Universidad de Granada y Caja General de Ahorros de Granada.

Cámaras Agrarias Locales: Estadísticas de cultivos.

COBO, F., CRUZ, S., GONZÁLEZ, M. (1992): “Privatización del monte y protesta campesina en Andalucía Oriental (1836-1920)". Agricultura y Sociedad, n 65, pp. 253-302.

Decreto de la Junta de Andalucía, no 73/1993 de 23 de mayo

Decreto de la Junta de Andalucía, no 50/1995 de 1 de marzo

Decreto de la Junta de Andalucía, no $127 / 98$ de 16 de junio (en vigor)

FERNÁNDEZ MUÑOZ, S.; MATA OLMO, R. (2000): "Pasado y presente de las repoblaciones forestales en montes de sociedades de vecinos", en Estudios Geográficos, LXI, 240, pp. 461-486.

GÁMEZ NAVARRO, J. (1995): El Espacio geográfico de Guadix: aprovechamientos agrarios, propiedad y explotación. Universidad de Granada y Caja General de Ahorros de Granada, col. Monográfica, $\mathrm{n}^{\mathrm{o}} 211$.

GÓMEZMENDOZA, J. (1992): “El marco jurídico y las formas de explotación de los montes en España”. En Actas del VI Coloquio de Geografía Rural. Madrid, Universidad Autónoma de Madrid, Departamento de Geografía, 1991, pp. 79-144.

GÓMEZ, J. y MATA, R. (1992): “Actuaciones forestales públicas desde 1940. Objetivos, criterios y resultados". Agricultura y Sociedad, n.1 65, pp. 15-64.

GORDO, J. y GIL, L. (1991): “Los bosques de coníferas de Castilla y León”, El Campo, Boletín de Información Agraria, nº. 120, abril-junio 1991, pp. 86-93.

HONTORIA, C.; ALMORZÓ, J.; GALLARDO, J. (2002): "Evaluación de tierras para reforestación (Horche, Guadalajara) mediante un índice de productividad agraria", en Estudios Geográficos, LXIII, 246, pp. 33-48. 
INFORMES 1999 a 2002. MEDIO AMBIENTE EN ANDALUCÍA. Consejería de Medio Ambiente. Junta de Andalucía. Sevilla.

LÓPEZ ESTUDILLO, A. (1992): "Los montes públicos y las diversas vías de su privatización en el siglo XIX". Agricultura y Sociedad, n 65, pp. 65-99.

MEMORIAS anuales. La agricultura y la Pesca en Andalucía. Consejería de Agricultura y Pesca. Junta de Andalucía. Sevilla.

PLAN Forestal Andaluz (1989). Junta de Andalucía. Consejería de Agricultura, Instituto Andaluz de Reforma Agraria, Agencia de Medio Ambiente. Sevilla.

PÉREZ VILARIÑO, J. (1998): “Construcción social del monte y desarrollo cooperativo del sector forestal”, en Agricultura y Sociedad, n 85, pp. 15-42.

Reglamento del Consejo (CEE) 2080/92 de 30 de junio

Reglamento del Consejo (CEE) 1527/99 de 17 de mayo

Real Decreto del MAPA, no 373/93 de 12 de marzo

Orden del MAPA, de 20 de marzo de 1995 y Orden de 28 de diciembre de 1995

Real Decreto del MAPA, n $152 / 96$ de 2 de febrero

Real Decreto del MAPA, nº 6/2001 de 12 de enero

RODRÍGUEZ MARTÍNEZ, F. (1984): Granada: medio físico y desarrollo. Instituto de Desarrollo Regional. Universidad de Granada.

RUEDA RAMOS, J. (1991): "El sector forestal”. El Campo, Boletín de Información Agraria,

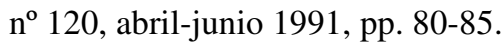

SILVA PÉREZ, R. (1995): "Las acciones forestales en el seno de la PAC. Consecuencias para Andalucía del programa de reforestación". Revista de Estudios Andaluces, $\mathrm{n}^{\circ} 21$, pp. 85-104. Sevilla. 